\title{
Challenge models to assess new therapies in chronic obstructive pulmonary disease
}

This article was published in the following Dove Press journal:

International Journal of COPD

12 September 2012

Number of times this article has been viewed

\author{
René van der Merwe' \\ Nestor A Molfino ${ }^{2,3}$ \\ 'Respiratory Clinical Development, \\ Medlmmune Ltd, Cambridge, UK; \\ ${ }^{2}$ Respiratory Clinical Development, \\ Medlmmune, LLC, Gaithersburg, \\ MD, USA, ${ }^{3}$ KaloBios Pharmaceuticals, \\ South San Francisco, CA, USA
}

\begin{abstract}
Chronic obstructive pulmonary disease (COPD) is a major cause of morbidity and mortality. Current therapies confer partial benefits either by incompletely improving airflow limitation or by reducing acute exacerbations, hence new therapies are desirable. In the absence of robust early predictors of clinical efficacy, the potential success of novel therapeutic agents in COPD will not entirely be known until the drugs enter relatively large and costly clinical trials. New predictive models in humans, and new study designs are being sought to allow for confirmation of pharmacodynamic and potentially clinically meaningful effects in early development. This review focuses on human challenge models with lipopolysaccharide endotoxin, ozone, and rhinovirus, in the early clinical development phases of novel therapeutic agents for the treatment and reduction of exacerbations in COPD.
\end{abstract}

Keywords: chronic obstructive pulmonary disease, challenge models, therapy assessment

\section{Introduction}

The Global Initiative for Chronic Obstructive Lung Disease defines chronic obstructive pulmonary disease (COPD) as a

... common preventable and treatable disease characterized by persistent airflow limitation that is usually progressive and associated with an enhanced chronic inflammatory response in the airways and the lung to noxious particles or gases. Exacerbations and comorbidities contribute to the overall severity in individual patients. ${ }^{1}$

Exacerbations are associated with increased airway and systemic inflammation, which lead to airway wall edema, sputum plugging, and bronchoconstriction.

COPD remains a major global health and economic burden that is expected to be the third leading cause of death, and the fifth leading cause of disability by $2020 .{ }^{1}$ In 2010, COPD accounted for $\$ 49.9$ billion in health care expenditures in the United States alone ( $\$ 29.5$ billion in direct health care expenditures, $\$ 8.0$ billion in indirect morbidity costs, and $\$ 12.4$ billion in indirect mortality costs). ${ }^{2}$ In Europe, COPD accounts for 10.3 billion Euros in health care spending a year. ${ }^{3}$

Pharmacological therapy is used to control symptoms, as well as to reduce exacerbations, and to improve exercise tolerance. Ambulatory COPD patients are currently treated with long-acting bronchodilators and inhaled corticosteroids, along with systemic corticosteroids during exacerbations. There is a pressing need to develop novel approaches for the treatment of COPD and the prevention or reduction of acute exacerbations of COPD. Existing therapies give partial benefits either by incompletely improving airflow limitation or reducing acute exacerbations, hence the need for newer, more
Correspondence: René van der Merwe Medlmmune, Ltd, Milstein Building, Granta Park, Cambridge, CB2I 6GH, UK Tel +44 01223895942

Fax +44 01223894663

Email vandermerwer@medimmune.com 
effective therapies. Evidence that existing medications reduce lung function decline in the long term has been inconclusive. The TORCH study ${ }^{4}$ investigated the effects of combined salmeterol plus fluticasone, either component alone, and placebo, on the rate of postbronchodilator forced expiratory volume in 1 second $\left(\mathrm{FEV}_{1}\right)$ decline. The investigators found that salmeterol plus fluticasone reduced the rate of $\mathrm{FEV}_{1}$ decline by $16 \mathrm{~mL} /$ year compared with placebo. Despite this large study, a meta-analysis conducted by Soriano et $\mathrm{al}^{5}$ concluded that inhaled corticosteroids showed a significant improvement in lung function decline compared with placebo at 3 months, however, after 6 months there was no significant difference between placebo and inhaled corticosteroid treatment.

One of the main challenges in developing new therapeutic agents for the treatment or prevention of acute exacerbations of COPD is that their potential success cannot be entirely known until the investigational therapies enter relatively large Phase II studies, assessing clinical outcome over a 3- to 6-month period or longer. ${ }^{6,7}$

This article reviews the experimental challenges that can be performed relatively early in drug development for the treatment of COPD in order to obtain preliminary signals of safety and efficacy in humans. These challenge models are representative of the local inflammatory response caused by an exacerbation of COPD; however it is important to note that these models do not reflect the actual exacerbation milieu. The models chosen are those models that have successfully been used to date in COPD drug development. Depending on the dose given during inhalation, these challenge models may also cause local and systemic inflammation, thus making them ideal for assessing the inflammatory processes in the lungs during an exacerbation and the potential therapeutic benefit of novel agents, as they mimic the local inflammatory response in the lung during an exacerbation.

\section{Lipopolysaccharide challenge}

Lipopolysaccharide (LPS) is a macromolecular cell wall surface antigen of Gram-negative bacteria. It is made up of three components: the $\mathrm{O}$ antigen (or $\mathrm{O}$ polysaccharide) side chain, the core oligosaccharide, and the lipid A moiety. ${ }^{8}$ LPS is an extremely biologically active substance and has been used for many years in preclinical and clinical research, due to its role in activating many transcription factors. In the serum, LPS binds to a lipid-binding protein, which facilitates the association between LPS and CD14 on the cell membranes. This in turn facilitates the transfer of LPS to the TRL4/MD2 complex (Figure 1). ${ }^{9}$ This triggers a signaling cascade in macrophage lineage and endothelial cells, resulting in the

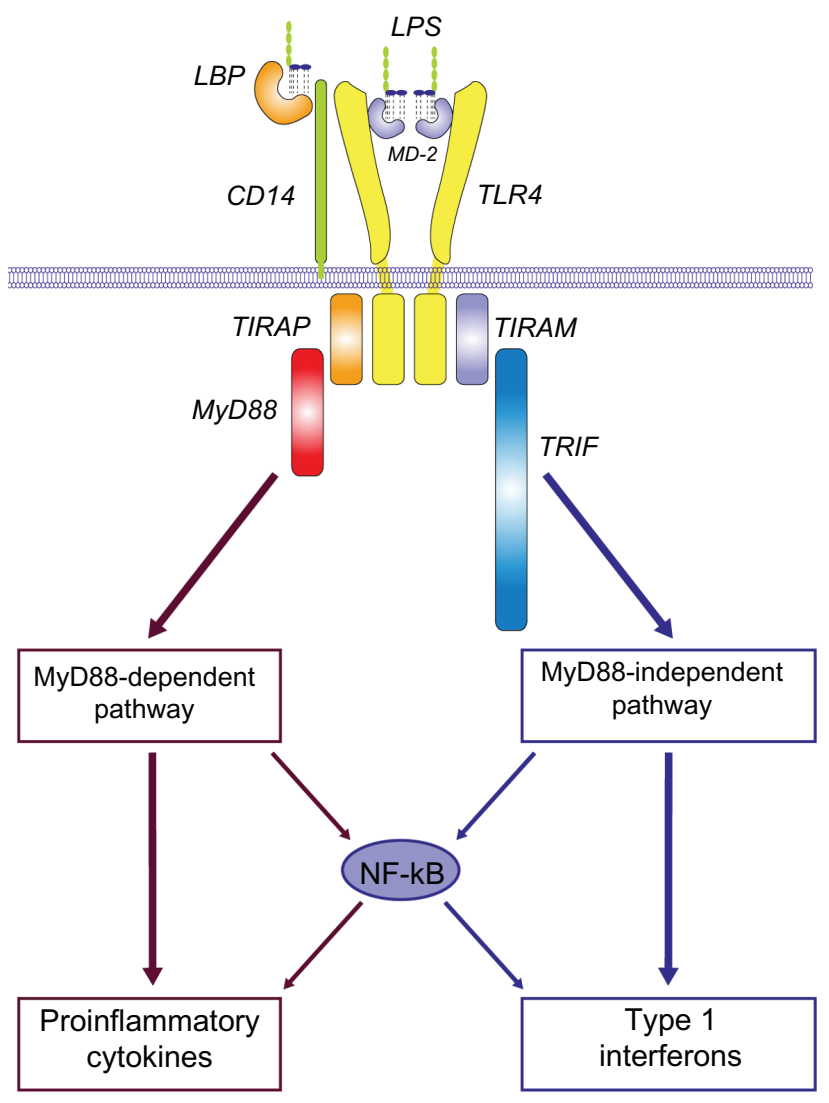

Figure I Lipopolysaccharide/TLR4 signalling lipopolysaccharide recognition.

Notes: Overview of LPS/TLR4 signalling LPS recognition is facilitated by lipopolysaccharide-binding protein and CDI4, and is mediated by TLR4/MD-2 receptor complex. LPS/TLR4 signalling can be separated into MyD88-dependent and MyD88-independent pathways, which mediate the activation of proinflammatory cytokine and type I interferon genes.

Copyright (C) 2008, Elsevier. Reprinted with permission from Lu YC, Yeh WC, Ohashi PS. LPS/TLR4 signal transduction pathway. Cytokine. 2008;42(4): 145-151.9

Abbreviations: LPS, lipopolysaccharide; LBP, ligand-binding protein; CD, cluster of differentiation; MyD88, myeloid differentiation primary response gene 88; TLR4, toll-like receptor 4; TIRAP, toll-interleukin-I receptor domain-containing adaptor protein; TRIF, toll-interleukin-I receptor domain-containing adaptor inducing IFN-b; TRAM, TRIF-related adaptor molecule; NF-kB, nuclear factor kappa beta.

secretion of proinflammatory cytokines and nitric oxide, and the activation of complement and the coagulation systems that contribute to characteristic features of inflammation, and with excessive stimulation, "endotoxic shock."

In monocytes and macrophages, LPS triggers the production of powerful inflammatory mediators including cytokines (eg, interleukin [IL]-1, IL-6, IL-8, tumor necrosis factor [TNF]- $\alpha$ and platelet-activating factor), which stimulate production of prostaglandins and leukotrienes. In addition, LPS activation results in enhanced macrophage phagocytic and cytotoxic activity. Activation of alternative complement pathway factors $\mathrm{C} 3 \mathrm{a}$ and $\mathrm{C} 5 \mathrm{a}$ induce histamine release, and affect neutrophil chemotaxis and accumulation. Kinin activation releases bradykinins and other vasoactive peptides, which cause hypotension. The release of these mediators and 
subsequent systemic response make LPS a powerful research tool in evaluating inflammatory pathways.

Healthy subjects inhaling endotoxin show a systemic and pulmonary inflammatory response, recruiting neutrophils and macrophages to the lung tissue. Inhalation of nebulized doses (up to $50 \mu \mathrm{g}$ ) of LPS via a dosimeter in healthy volunteers, leads to an increase in temperature, blood C-reactive protein (CRP), blood and sputum neutrophils, blood monocytes and lymphocytes, and blood and sputum proinflammatory mediators, including: IL-8, TNF $\alpha$, myeloperoxidase (MPO), matrix metalloproteinase-9, IL-6, IL-1 $\beta$, monocyte chemotactic protein-1, and macrophage inflammatory protein- $1 \beta .{ }^{10,11}$

Bronchial segmental instillation induces an early phase response (0-24 hours), resulting in a statistically significant increase in neutrophils, TNF, IL-1 $\beta$, IL-1R antagonist, IL-6, and granulocyte colony-stimulating factor. Neutrophils, macrophages, and monocytes increase 24-48 hours post instillation. ${ }^{11,12}$

Intranasal LPS challenge may be the least invasive and best tolerated model. Clinical symptoms are minimal; however, very little or no data have been published to date using this model. Further validation of the intranasal model needs to be performed to compare it to the LPS inhalation challenge model, to better understand the relevance of the LPS-triggered nasal inflammation to the phenomena that occur in the central and distal airways in COPD.

Many of the effects of exogenous LPS can be blocked by medications. In one study, pretreatment with oral prednisolone or cilomilast had no effect on the local LPS-induced inflammatory response in the lung; ${ }^{13}$ pretreatment with prednisolone alone significantly inhibited the LPS-induced CRP response. Cilomilast attenuated the increase in CRP, but not significantly. Similarly, in another study, subjects who received simvastatin $40-80 \mathrm{mg}$ demonstrated a reduction in neutrophils, MPO, TNF $\alpha$, matrix metalloproteinase-7, -8, and -9 in the bronchoalveolar lavage fluid (BALF), as well as a reduction in plasma CRP, versus placebo. ${ }^{14}$ Hohlfeld et $\mathrm{al}^{15}$ used LPS to show that roflumilast reduced the influx of total cells, neutrophils, and eosinophils into the airways of healthy subjects after segmental challenge with endotoxin, with statistical significance.

It is important to remember that inhaled LPS challenge is a model of acute neutrophilic inflammation and not a model of COPD. ${ }^{16}$ The model can be used to understand the biological effects of compounds that inhibit the LPS pathway (Table 1).

\section{Ozone challenge}

Ozone $\left(\mathrm{O}_{3}\right)$ is a major component of urban environmental air pollution. It is formed in the troposphere from primary precursor pollutants. In the presence of light, $\mathrm{NO}_{2}$ is cleaved by sunlight to $\mathrm{NO} \bullet+\mathrm{O} \bullet$, allowing the formation of $\mathrm{O}_{3}$ $\left(\mathrm{O}_{2}+\mathrm{O} \bullet\right)$ (Figure 2). In epidemiological studies, $\mathrm{O}_{3}$ levels have been associated with exacerbations of asthma, COPD, and pneumonia. ${ }^{17-19}$ Experimental $\mathrm{O}_{3}$ exposure in healthy human subjects is known to elicit a reversible impairment in lung function, as well as acute proximal airways neutrophilic inflammation, and an increase in the concentration of several cytokines and mediators of inflammation within the airways. $^{20}$

Table I Compounds tested in LPS model and development progression

\begin{tabular}{|c|c|c|c|c|c|}
\hline Compounds & $\begin{array}{l}\text { Administration } \\
\text { route of IMP }\end{array}$ & LPS model & $\begin{array}{l}\text { Effects on inflammatory } \\
\text { markers }\end{array}$ & Progression to Phase III & Sources \\
\hline Prednisolone & Oral & Inhaled & $\begin{array}{l}\text { No effect on lung inflammation; } \\
\text { significant reduction in CRP }\end{array}$ & Yes, successful NDA & 13 \\
\hline $\begin{array}{l}\text { Cilomilast } \\
\text { (PDE4I, GlaxoSmithKline) }\end{array}$ & Oral & Inhaled & $\begin{array}{l}\text { No effect on lung inflammation, } \\
\text { reduction in CRP }(P=0.09)\end{array}$ & $\begin{array}{l}\text { Yes, development terminated } \\
\text { due to lack of efficacy }\end{array}$ & 13 \\
\hline Fluticasone & Inhaled & Inhaled & $\begin{array}{l}\text { Significant reduction in neutrophils } \\
\text { and eosinophils; no effect on } \\
\text { soluble inflammatory markers }\end{array}$ & Yes, successful NDA & 16 \\
\hline $\begin{array}{l}\text { Roflumilast } \\
\text { (PDE4I, Nycomed) }\end{array}$ & Oral & Segmental & $\begin{array}{l}\text { Significant reduction in neutrophils } \\
\text { and eosinophils; no effect on } \\
\text { soluble inflammatory markers } \\
\text { in bronchoalveolar lavage }\end{array}$ & $\begin{array}{l}\text { Yes, successful NDA } \\
\text { and Market Authorization } \\
\text { Application }\end{array}$ & 15 \\
\hline Simvastatin & Oral & Inhaled & $\begin{array}{l}\text { Reduction in neutrophils, MPO, } \\
\text { TNF } \alpha, \text { MMP-7, }-8 \text {, and }-9 \text { in the } \\
\text { BALF; reduction in plasma CRP }\end{array}$ & $\begin{array}{l}\text { Two Phase II clinical trials are } \\
\text { ongoing in acute lung injury; } 4 \text { large } \\
\text { RCTs in COPD are ongoing }\end{array}$ & 62 \\
\hline
\end{tabular}

Abbreviations: LPS, lipopolysaccharide; IMP, investigational medicinal product; CRP, C-reactive protein; NDA, new drug application; PDE4I, phosphodiesterase type 4 inhibitor; MPO, myeloperoxidase; TNF, tumor necrosis factor; MMP, matrix metalloproteinase; BALF, bronchoalveolar lavage fluid; RCTs, randomized controlled trials; COPD, chronic obstructive pulmonary disorder. 


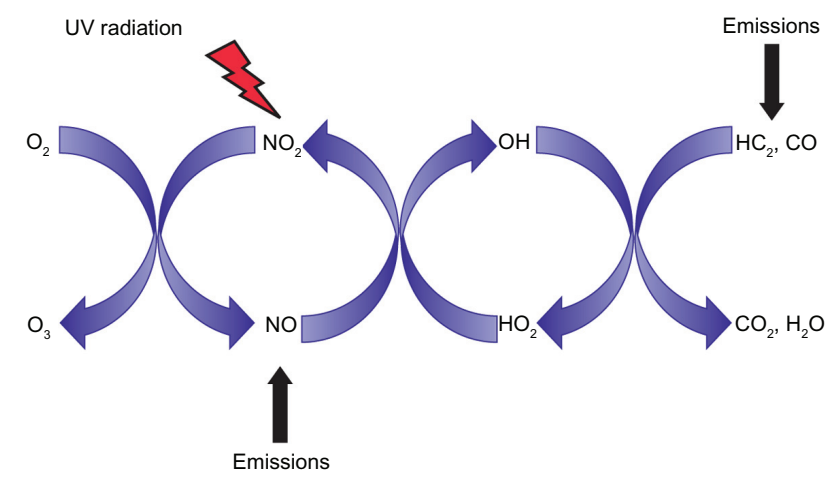

Figure 2 Formation of $\mathrm{O}_{3}$ in the troposphere. $\mathrm{NO}_{2}$ is cleaved by sunlight to $\mathrm{NO} \cdot+\mathrm{O} \cdot$ allowing the formation of $\mathrm{O}_{3}\left(\mathrm{O}_{2}+\mathrm{O} \cdot\right)$.

In the first reported study of the inflammatory effects of low-level $\mathrm{O}_{3}$ exposure ( 80 ppb $\mathrm{O}_{3}$ for 6.6 hours) in healthy volunteers, ${ }^{21}$ there were statistically significant increases in polymorphononuclear neutrophils, prostaglandin $\mathrm{E}_{2}$, lactate dehydrogenase, IL-6, $\alpha 1$-antitrypsin, and decreased phagocytosis via the complement receptor. This is similar to a more recent study with low-level exposure to $\mathrm{O}_{3}$ at 80 ppb for 6.6 hours, ${ }^{22}$ in which there were increased airway neutrophils, monocytes, and dendritic cells, as well as modifications of the expression of CD14, HLA-DR, CD80, and CD86 on monocytes. In another study examining whether circulating CD11b plays a role in the inflammatory response following inhaled $\mathrm{O}_{3}$ exposure, 22 volunteers underwent controlled exposure to $\mathrm{O}_{3}(400 \mathrm{ppb}$ for 2 hours $)$ and to clean air on two separate occasions. ${ }^{23}$ Induced sputum collected from subjects exposed to $\mathrm{O}_{3}$ revealed marked neutrophilia, and increased expression of mCD14 on airway macrophages and monocytes. Circulating CD11b levels also predicted the magnitude of the airway neutrophil response following inhaled $\mathrm{O}_{3}$ exposure.

A number of different classes of therapeutic agents have been studied in the $\mathrm{O}_{3}$ challenge model in healthy volunteers. Therapeutic classes include corticosteroids (administered orally and by inhalation) and nonsteroidal anti-inflammatory drugs. More recently, studies investigating the effects of CXC chemokine receptor (CXCR) 1, 2 antagonists have been reported. ${ }^{24-28}$

Holz et $\mathrm{al}^{24}$ conducted a double-blind, double-dummy, placebo-controlled, three-period crossover study. Eighteen healthy subjects, who had been shown at screening to produce more than a $10 \%$ increase in sputum neutrophils in response to exposure to $250 \mathrm{ppb} \mathrm{O}_{3}$, were randomly assigned to receive alternating single orally inhaled doses of fluticasone $2 \mathrm{mg}$, $50 \mathrm{mg}$ of prednisolone orally, and placebo at least 2 weeks apart. Compared with placebo, pretreatment with inhaled or oral corticosteroids resulted in a significant reduction of sputum neutrophils, by $62 \%$ and $64 \%$, respectively. This was associated with statistically significant reductions in sputum MPO, by $55 \%$ for inhaled corticosteroids and $42 \%$ for oral steroids. Compared with placebo, there was a mean reduction in sputum IL-8 levels, by $49 \%$ after inhaled corticosteroids and $34 \%$ after oral corticosteroids.

Similar results were obtained in a study conducted by Alexis et al. ${ }^{25}$ In subjects receiving fluticasone $0.5 \mathrm{mg}$ and $2 \mathrm{mg}$, sputum neutrophilia was significantly reduced by $18 \%$ and $35 \%$, respectively. The following inflammatory markers were also significantly reduced in a dose-dependent manner in subjects receiving fluticasone: CD11b, mCD14, CD64, CD16, HLA-DR, and CD86 on sputum monocytes. Serum Clara cell protein 16 levels (a marker of pulmonary damage) were significantly increased post- $\mathrm{O}_{3}$ challenge.

Schelegle et $\mathrm{al}^{26}$ pretreated healthy volunteers with indomethacin, which was shown to significantly reduce $\mathrm{O}_{3}$-induced decrements in $\mathrm{FEV}_{1}$ and forced vital capacity, when compared to no drug or placebo. This was associated with reductions in subjective symptoms of cough, shortness of breath, and throat tickle on indomethacin treatment, suggesting that cyclooxygenase products play a partial role in subjective symptoms associated with $\mathrm{O}_{3}$ exposure. Hazucha et $\mathrm{al}^{29}$ demonstrated a similar reduction of $\mathrm{O}_{3}$-induced decrements in $\mathrm{FEV}_{1}$ and forced vital capacity following singledose treatment with either $200 \mathrm{mg}$ or $800 \mathrm{mg}$ of ibuprofen compared to placebo, which was associated with reduced post- $\mathrm{O}_{3}$ BALF levels of prostaglandin $\mathrm{E}_{2}$, thromboxane $\mathrm{B} 2$, and IL-6.

SCH527123 is a novel, selective, oral CXC chemokine receptor 2 antagonist that inhibits neutrophil activation and modulates neutrophil trafficking in animal models. Eighteen healthy $\mathrm{O}_{3}$ responders ( $>20 \%$ increase in sputum neutrophils) underwent $\mathrm{O}_{3}$ challenge tests $(250 \mathrm{ppb}, 3$ hours intermittent exercise) 1 hour after the last treatment dose, and sputum was induced at 3 hours postchallenge ${ }^{27}$ following SCH527123 treatment. The $\mathrm{O}_{3}$ challenge resulted in statistically significantly lower sputum neutrophil counts $\left(0.136 \times 10^{6} \mathrm{~mL}^{-1}\right)$ compared with prednisolone $\left(0.846 \times 10^{6} \mathrm{~mL}^{-1} ; P=0.001\right)$ or placebo $\left(2.986 \times 10^{6} \mathrm{~mL}^{-1} ; P=0.001\right)$. Comparable results were obtained for total cell count, percentage of sputum neutrophils, and for IL-8 and myeloperoxidase in sputum supernatant. Post challenge, SCH527123 inhibited neutrophilia in peripheral blood, but significantly less than in sputum.

Gaga et $\mathrm{al}^{30}$ investigated the use of SCH527123I in subjects with severe neutrophilic asthma. When averaged 
over the 4-week treatment period, sputum neutrophils were significantly reduced in the active group by $57 \%$ compared to placebo $(P=0.01)$. There were fewer mild exacerbations ( 1.3 vs $2.25 ; P=0.05)$, and there was a trend towards fewer severe exacerbations in the SCH527123 group. The Asthma Control Questionnaire score was improved by 0.42 points in the active group compared with the placebo-treated group $(P=0.053)$, although the difference did not reach clinical significance, and no changes were observed in $\mathrm{FEV}_{1}$. This shows that in asthma, the $\mathrm{O}_{3}$ challenge model has proved useful in demonstrating inhibition of neutrophil numbers, associated with a clinical meaningful effect.

More recently, in a randomized, double-blind, placebo controlled three-way crossover trial of the CXCR2 antagonist SB-656933, 24 healthy nonsmoking male subjects were randomly assigned to receive a single dose of $50 \mathrm{mg}, 150 \mathrm{mg}$, or placebo, 1 hour prior to $\mathrm{O}_{3}$ challenge. ${ }^{31}$ Single doses of SB-656933 reduced $\mathrm{O}_{3}$-induced airway inflammation in a dose-dependent manner. There were corresponding reductions in myeloperoxidase levels in the sputum supernatant, by 32.8\% (confidence interval: 9.2, 50.3) and 50.5\% (confidence interval: $33.3,63.3)$.

Studies in COPD have been conducted using $\mathrm{O}_{3}$ concentrations in the range of $120-250 \mathrm{ppb}$ with 7.5-15 minutes of exercise every 30 minutes, aiming to maintain a ventilatory rate of between $20-30 \mathrm{~L} / \mathrm{min} .{ }^{32-34}$ In a study of nine subjects with COPD and ten age-matched controls, Gong et $\mathrm{al}^{35}$ found an increase in specific airway resistance and a statistically significant decrease in $\mathrm{FEV}_{1}$ in the COPD subjects versus the age-matched controls.

In summary, $\mathrm{O}_{3}$ challenge has been well tolerated in healthy volunteers and in older subjects, as well as subjects with asthma or COPD. The $\mathrm{O}_{3}$-challenge model potentially provides critical decision-making data in understanding whether new compounds have the desired biological effect in healthy volunteers and patients with COPD; hence it can de-risk decisions to move forwards into large Phase II safety and efficacy trials.

\section{Rhinovirus challenge}

Rhinovirus is responsible for the common cold and is spread through infected respiratory secretions from one person to another. Human rhinovirus (HRV) replicates at $33^{\circ} \mathrm{C}-35^{\circ} \mathrm{C}$ and thus has been linked to upper airway infections, where mucosal surfaces are cooler. Evidence exists that HRV is not limited to the upper airways. Gern et $\mathrm{al}^{36}$ detected HRV using reverse transcription polymerase chain reaction in both nasal secretions and BALF, in healthy subjects after experimental infection with rhinovirus 16.
HRV binds to intracellular adhesion molecule (ICAM)-1, the major HRV receptor. ${ }^{37}$ The low-density-lipoprotein receptor $^{38}$ binds to a minor group of HRV (HRV2). The gene for ICAM-1 maps to human chromosome 19, as do the genes for a number of other picornavirus receptors.

Several studies have shown induction of proinflammatory genes implicated in neutrophil activation following rhinovirus induction of bronchial epithelial cells (eg, IL-8 regulated by NF- $\kappa \beta$ signaling pathways and Groo $\alpha){ }^{39-41}$

Rhinovirus infection of epithelial cells leads to the release of proinflammatory cytokines and chemokines including IL-6 and IL-8. Chemokines attract inflammatory cells (eg, neutrophils, eosinophils). These cells release toxic products, stimulating mucus production and leading to tissue damage, with possible long-term loss of lung function. Some mediators, such as endothelin-1, have a direct effect in causing bronchoconstriction and vasoconstriction, resulting in airflow obstruction and impaired gas exchange.

Healthy subjects, subjects with asthma, and subjects with allergic asthma have been intensively studied in clinical trials inoculating them with rhinovirus 16 or other rhinovirus serotypes. ${ }^{42-44}$ These studies demonstrated that rhinovirus infection of the lower airways is common after experimental inoculation.

Several studies looking at causes of exacerbations in COPD have shown that viruses account for up to $60 \%$ of exacerbations, and that HRV is numerically the most important virus type..$^{30,45-50}$ Figure 3 depicts the total viral and HRV exacerbation rate in seven exacerbation studies. Other viruses associated with acute exacerbations of COPD are coronavirus, influenza A and B, parainfluenza, adenovirus, and respiratory syncytial virus. ${ }^{45,51-55}$

To develop a model of viral exacerbation in subjects with COPD, Mallia et $\mathrm{al}^{56}$ conducted a virus dose-escalating study infecting four COPD subjects with rhinovirus. In this study, the median tissue culture infective dose (TCID50) of rhinovirus was administered by the inhaled route using a nebulizer, to elicit a COPD exacerbation. Although there was a decrease in $\mathrm{FEV}_{1}(16 \%)$ and peak expiratory flow (12\%) maximal on day 9 , there was not a statistically significant increase in total sputum cell count or peripheral neutrophil count. Symptoms of cold and lower respiratory tract symptoms, as well as lung function changes that are characteristic of viral-induced exacerbations of COPD, were observed. There was an increase, although not statistically significant, in the proinflammatory cytokines IL-6 and IL-8.

In another study, there were significant increases in total respiratory scores in both COPD subjects and 


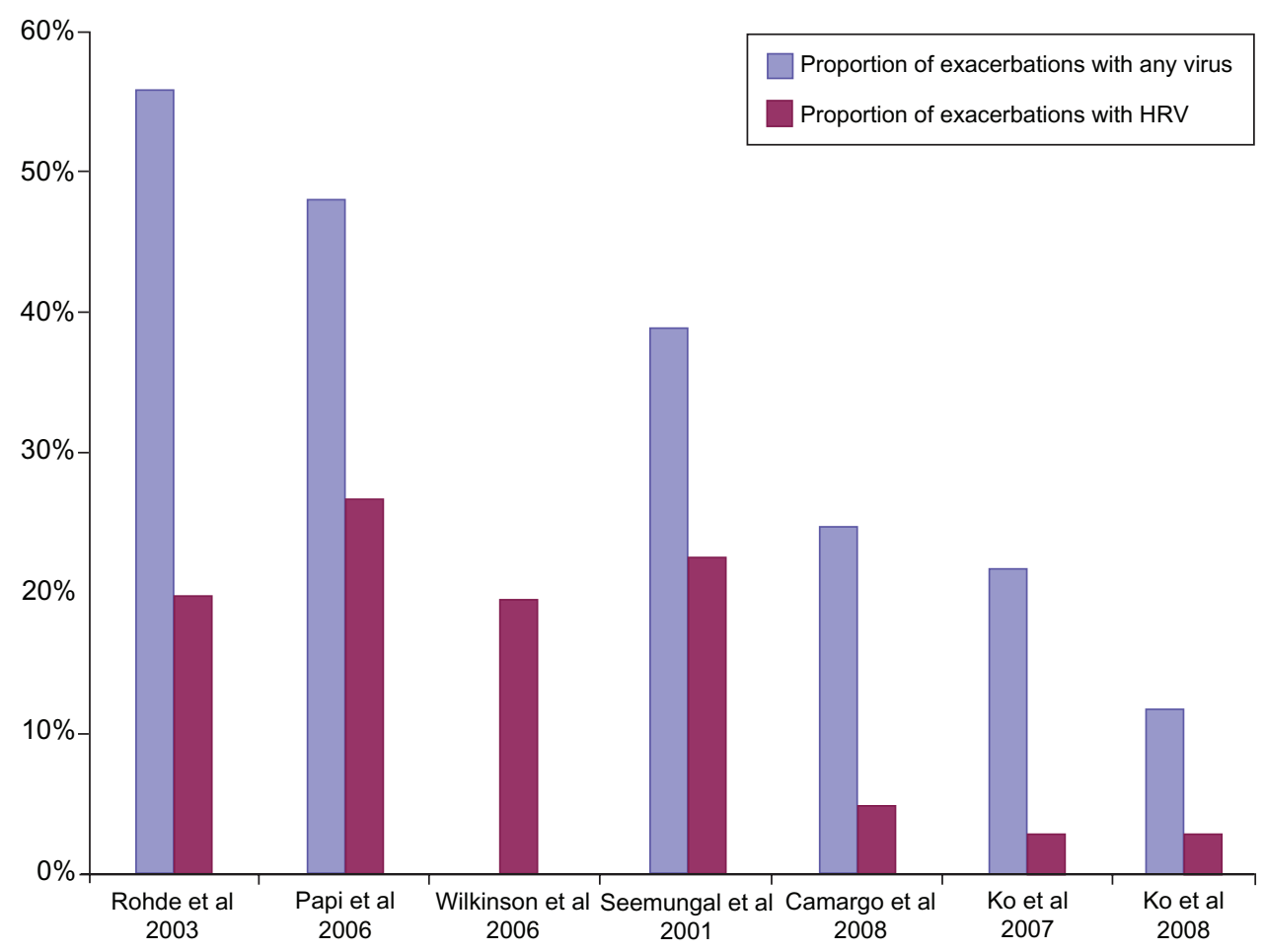

Figure 3 Proportion of subjects with viral exacerbations.

Note: Total viral and human rhinovirus exacerbation rates in seven studies of exacerbations of chronic obstructive pulmonary disorder. ${ }^{45-50,54}$

healthy controls. ${ }^{57}$ Peak expiratory flow fell by $23.5 \mathrm{~mL}$ in the controls $(P=$ not significant $)$ and by $50.5 \mathrm{~mL}(P<0.05)$ in the COPD patients. Peripheral white cell counts and neutrophils increased in both groups. Sputum neutrophil count also increased in the COPD patients but not in the controls. More recently, both the upper and lower symptom scores were found to be significantly higher in the COPD subjects. ${ }^{58}$ In this study, ten of the 11 infected COPD subjects met the criteria defining an exacerbation of COPD. Subjects in the COPD group demonstrated significant decreased peak expiratory flow from baseline, while those in the control group did not. The blood and sputum showed a significant increase in peripheral neutrophils in the COPD subjects but not the controls. However, CRP was significantly increased in both groups on day 5. Subjects in the COPD group had significantly increased sputum neutrophil elastase levels over baseline on days 9 and 15, as well as IL-8 levels on day 9 . Sputum neutrophil elastase levels were significantly higher in subjects with COPD, compared with control subjects on days 9-15. To date, only one laboratory has published on this model and as such, the data should be interpreted with caution.

The main advantage of this model is that it will give a clear understanding and insight into the molecular and cellular inflammatory processes that take place during a viral-associated exacerbation of COPD. There are no published data to date on the effect of pharmacological interventions in this model.

The rhinovirus challenge model has the potential for use as a preclinical and clinical tool to identify and investigate novel drug targets and establish whether new therapeutic agents have potential clinical utility. These include (but are not limited to) targets against soluble ICAM-1 and thus inhibit interaction of HRV with ICAM-1, ${ }^{59,60}$ inhibitors of rhinovirus RNA-dependent RNA polymerases 3D, ${ }^{61}$ activators of retinoic acid-inducible gene $1,{ }^{62}$ inhibitors of rhinovirus capsid protein VP-163 and inhibitors of different rhinovirus proteases (eg, 2A, 3C) ${ }^{64,65}$ Currently, this is the only model that reflects the underlying mechanism of viral exacerbations of COPD.

\section{Discussion}

The use of challenge models has the potential to significantly inform early decision making, before embarking on longterm Phase II and III clinical trials designed to test interventions that may treat or avert exacerbations of COPD. Although challenge models are good predictive models of acute exacerbations of COPD, there are ethical considerations associated with inducing exacerbations in subjects with COPD. Therefore, safety boards may be advised to only consider 
subjects with mild COPD for inclusion in these studies. Healthy subjects could be used as an alternative, when determining the effects of a developmental drug's mechanism of action on lung inflammation. The LPS and $\mathrm{O}_{3}$ models have been used successfully in healthy subjects. ${ }^{13-15,22,24,26-28}$ As these models represent the local inflammation in the lung during an exacerbation, and test the mechanism of action of potential novel drugs, these data may be used for future decision making.

The LPS challenge model is the best validated model in subjects with COPD. Pharmaceutical companies have used LPS models as a means to establish proof of principle early during the clinical development process, because they are relatively simple to perform and have few adverse events. This model is cost effective because it can be conducted in healthy subjects, who are easy to recruit. LPS challenge data, whether positive or negative, can provide valuable information to aid investment decision making. One disadvantage of the LPS model is that it is a model of lung inflammation, but not of the disease state, thus preclinical validation of the developmental drug's effects on LPS pathways is essential. For anti-inflammatory targets that are involved in the tolllike receptor $4, \mathrm{NF}-\kappa \beta$ pathway, the LPS challenge model is the model of choice.

Despite the longstanding knowledge and understanding of the adverse effects of $\mathrm{O}_{3}$ on pulmonary biology, the use of $\mathrm{O}_{3}$ as a challenge model to assess the potential of new drugs for the prevention of acute exacerbations in COPD, is relatively new. The model has been shown to be safe and to have few side effects in healthy volunteers, and in patients with asthma and COPD. ${ }^{24,25,28,66}$ Additionally, it is reliable and reproducible. It has been used successfully to generate biological effect and systemic effect for fluticasone and the CXCR2 antagonists, SCH527123 and SB-656933. ${ }^{27,31}$ A limitation of the $\mathrm{O}_{3}$ model is that it has yet to be determined whether inhibition of neutrophilia translates into clinical benefits for patients with COPD. Preliminary data indicate that inhibition of the neutrophil response following $\mathrm{O}_{3}$ challenge may be associated with beneficial changes in system scores obtained in subjects with COPD.

Challenge with rhinovirus 16 to elicit mild exacerbations in subjects with COPD appears to be safe and well tolerated, but only a few COPD subjects have been exposed to this model. The observation that $\mathrm{FEV}_{1}$ does not always return to baseline after inducing an exacerbation in COPD subjects may call to question the feasibility of using the challenge in a broader population of patients with COPD, in addition to raising ethical considerations. This remains an exciting model with a great deal of potential, as rhinovirus models are good predictive models of viral-induced acute exacerbations of COPD.

\section{Conclusion}

In order for pharmaceutical companies to succeed in the COPD arena, innovative approaches to clinical trial design and conduct are required that will generate critical, highquality proof of efficacy and biologic target engagement data to support early investment decision making, early drug termination, and facilitation of better-informed decisions regarding those drugs in which proof of effect has been clearly demonstrated. Challenge models in COPD, which expose fewer individuals for short periods of time to eliciting agents, may serve as surrogate of potential efficacy and thus may help early decision making and reduction in clinical development timelines.

\section{Acknowledgments}

This review is part of a dissertation for a master's degree (RvdM) at the University of Surrey, UK. Editorial assistance was provided by Lourdes Briz and Carrie Lancos, MedImmune, LLC.

\section{Disclosure}

Sponsorship: This manuscript was sponsored by MedImmune. Conflict of interest: RvdM is an employee of MedImmune; NAM is a former employee of MedImmune.

\section{References}

1. Global Initiative for Chronic Obstructive Lung Disease. Global strategy for the diagnosis, management and prevention of COPD; [updated 2011]. Available at: http://www.goldcopd.org. Accessed August 2, 2012.

2. American Lung Association. Chronic obstructive pulmonary disease (COPD) fact sheet; [updated Feb 2011]. Available at: http://www. lung.org/lung-disease/copd/resources/facts-figures/COPD-Fact-Sheet. html\#note_12. Accessed August 2, 2012.

3. European COPD Coalition. Key facts; [updated 2011]. Available at: http:// www.copdcoalition.eu/about-copd/key-facts. Accessed August 2, 2012.

4. Celli BR, Thomas NE, Anderson JA, et al. Effect of pharmacotherapy on rate of decline of lung function in chronic obstructive pulmonary disease: results from the TORCH study. Am J Respir Crit Care Med. 2008;178(4):332-338.

5. Soriano JB, Sin DD, Zhang X, et al. A pooled analysis of FEV1 decline in COPD patients randomized to inhaled corticosteroids or placebo. Chest. 2007;131(3):682-689.

6. Calverley PM, Anderson JA, Celli B, et al; for Torch investigators. Salmeterol and fluticasone propionate and survival in chronic obstructive pulmonary disease. $N$ Engl J Med. 2007;356(8):775-789.

7. Celli B, Decramer M, Kesten S, et al; for UPLIFT Study Investigators. Mortality in the 4-year trial of tiotropium (UPLIFT) in patients with chronic obstructive pulmonary disease. Am J Respir Crit Care Med. 2009;180(10):948-955.

8. Rietschel ET, Schade U, Jensen M, Wollenweber HW, Lüderitz O, Greisman SG. Bacterial endotoxins: chemical structure, biological activity and role in septicaemia. Scand J Infect Dis Suppl. 1982;31:8-21. 
9. Lu YC, Yeh WC, Ohashi PS. LPS/TLR4 signal transduction pathway. Cytokine. 2008;42(4):145-151.

10. Michel O, Nagy AM, Schroeven M, et al. Dose-response relationship to inhaled endotoxin in normal subjects. Am J Respir Crit Care Med. 1997;156(4 Pt 1):1157-1164.

11. Loh LC, Vyas B, Kanabar V, Kemeny DM, O'Connor BJ. Inhaled endotoxin in healthy human subjects: a dose-related study on systemic effects and peripheral CD4+ and CD8+ T cells. Respir Med. 2006;100(3):519-528.

12. O'Grady NP, Preas HL, Pugin J, et al. Local inflammatory responses following bronchial endotoxin instillation in humans. Am J Respir Crit Care Med. 2001;163(7):1591-1598.

13. Michel O, Dentener M, Cataldo D, et al. Evaluation of oral corticosteroids and phosphodiesterase-4 inhibitor on the acute inflammation induced by inhaled lipopolysaccharide in human. Pulm Pharmacol Ther. 2007;20(6):676-683.

14. ClinicalTrials.gov. Simvastatin therapy for moderate and severe COPD (STATCOPE); [updated April 23, 2012]. Available at: http:// clinicaltrials.gov/ct2/show/NCT01061671?term=NCT01061671\&ran $\mathrm{k}=1$. Accessed August 2, 2012.

15. Hohlfeld JM, Schoenfeld K, Lavae-Mokhtari M, et al. Roflumilast attenuates pulmonary inflammation upon segmental endotoxin challenge in healthy subjects: a randomized placebo-controlled trial. Pulm Pharmacol Ther. 2008;21(4):616-623.

16. Alexis NE, Peden DB. Blunting airway eosinophilic inflammation results in a decreased airway neutrophil response to inhaled LPS in patients with atopic asthma: a role for CD14. J Allergy Clin Immunol. 2001;108(4):577-580.

17. Bernstein JA, Alexis N, Barnes C, et al. Health effects of air pollution. J Allergy Clin Immunol. 2004;114(5):1116-1123.

18. Peden DB. Air pollution in asthma: effect of pollutants on airway inflammation. Ann Allergy Asthma Immunol. 2001;87(6 Suppl 3):S12-S17.

19. Committee of the Environmental and Occupational Health Assembly of the American Thoracic Society. Health effects of outdoor air pollution. Am J Respir Crit Care Med. 1996;153(1):3-50.

20. Aris RM, Christian D, Hearne PQ, Kerr K, Finkbeiner WE, Balmes JR. Ozone-induced airway inflammation in human subjects as determined by airway lavage and biopsy. Am Rev Respir Dis. 1993;148(5): 1363-1372.

21. Devlin RB, McDonnell WF, Mann R, et al. Exposure of humans to ambient levels of ozone for 6.6 hours causes cellular and biochemical changes in the lung. Am J Respir Cell Mol Biol. 1991;4(1):72-81.

22. Alexis NE, Lay JC, Hazucha M, et al. Low-level ozone exposure induces airways inflammation and modifies cell surface phenotypes in healthy humans. Inhal Toxicol. 2010;22(7):593-600.

23. Kehrl HR, Hazucha MJ, Solic JJ, Bromberg PA. Responses of subjects with chronic obstructive pulmonary disease after exposures to $0.3 \mathrm{ppm}$ ozone. Am Rev Respir Dis. 1985;131(5):719-724.

24. Holz O, Tal-Singer R, Kanniess F, et al. Validation of the human ozone challenge model as a tool for assessing anti-inflammatory drugs in early development. J Clin Pharmacol. 2005;45(5):498-503.

25. Alexis NE, Lay JC, Haczku A, et al. Fluticasone propionate protects against ozone-induced airway inflammation and modified immune cell activation markers in healthy volunteers. Environ Health Perspect. 2008;116(6):799-805.

26. Schelegle ES, Adams WC, Siefkin AD. Indomethacin pretreatment reduces ozone-induced pulmonary function decrements in human subjects. Am Rev Respir Dis. 1987;136(6):1350-1354.

27. Holz O, Khalilieh S, Ludwig-Sengpiel A, et al. SCH527123, a novel CXCR2 antagonist, inhibits ozone-induced neutrophilia in healthy subjects. Eur Respir J. 2010;35(3):564-570.

28. Nightingale JA, Rogers DF, Chung KF, Barnes PJ. No effect of inhaled budesonide on the response to inhaled ozone in normal subjects. Am J Respir Crit Care Med. 2000;161(2 Pt 1):479-486.

29. Hazucha MJ, Madden M, Pape G, et al. Effects of cyclo-oxygenase inhibition on ozone-induced respiratory inflammation and lung function changes. Eur J Appl Physiol Occup Physiol. 1996;73(1-2):17-27.
30. Gaga M, Nair PK, Hargreave F, Sadeh J, Chanez P. SCH527123, a novel treatment option for severe neutrophilic asthma. Am J Respir Crit Care Med. 2010;181:A6763.

31. Lazaar AL, Sweeney LE, MacdonaldAJ, Alexis NE, Chen C, Tal-Singer R. SB-656933, a novel CXCR2 selective antagonist, inhibits ex-vivo neutrophil activation and ozone-induced airway inflammation in humans. Br J Clin Pharmacol. 2011;72(2):282-293.

32. Linn WS, Fischer DA, Medway DA, et al. Short-term respiratory effects of $0.12 \mathrm{ppm}$ ozone exposure in volunteers with chronic obstructive pulmonary disease. Am Rev Respir Dis. 1982;125(6):658-663.

33. Solic JJ, Hazucha MJ, Bromberg PA. The acute effects of $0.2 \mathrm{ppm}$ ozone in patients with chronic obstructive pulmonary disease. Am Rev Respir Dis. 1982;125(6):664-669.

34. Linn WS, Shamoo DA, Venet TG, et al. Response to ozone in volunteers with chronic obstructive pulmonary disease. Arch Environ Health. 1983;38(5):278-283.

35. Gong H Jr, Shamoo DA, Anderson KR, Linn WS. Responses of older men with and without chronic obstructive pulmonary disease to prolonged ozone exposure. Arch Environ Health. 1997;52(1):18-25.

36. Gern JE, Galagan DM, Jarjour NN, Dick EC, Busse WW. Detection of rhinovirus RNA in lower airway cells during experimentally induced infection. Am J Respir Crit Care Med. 1997;155(3):1159-1161.

37. Greve JM, Davis G, Meyer AM, et al. The major human rhinovirus receptor is ICAM-1. Cell. 1989;56(5):839-847.

38. Hofer F, Gruenberger M, Kowalski H, et al. Members of the low density lipoprotein receptor family mediate cell entry of a minor-group common cold virus. Proc Natl Acad Sci U S A. 1994;91(5):1839-1842.

39. Griego SD, Weston CB, Adams JL, Tal-Singer R, Dillon SB. Role of p38 mitogen-activated protein kinase in rhinovirus-induced cytokine production by bronchial epithelial cells. J Immunol. 2000;165(9): 5211-5220.

40. Donninger H, Glashoff R, Haitchi HM, et al. Rhinovirus induction of the CXC chemokine epithelial-neutrophil activating peptide-78 in bronchial epithelium. J Infect Dis. 2003;187(11):1809-1817

41. Johnston SL, Papi A, Bates PJ, Mastronarde JG, Monick MM, Hunninghake GW. Low grade rhinovirus infection induces a prolonged release of IL-8 in pulmonary epithelium. J Immunol. 1998;160(12): 6172-6181.

42. Mosser AG, Vrtis R, Burchell L, et al. Quantitative and qualitative analysis of rhinovirus infection in bronchial tissues. Am J Respir Crit Care Med. 2005;171(6):645-651.

43. Papadopoulos NG, Bates PJ, Bardin PG, et al. Rhinoviruses infect the lower airways. J Infect Dis. 2000;181(6):1875-1884.

44. Fraenkel DJ, Bardin PG, Sanderson G, Lampe F, Johnston SL, Holgate ST. Lower airways inflammation during rhinovirus colds in normal and in asthmatic subjects. Am J Respir Crit Care Med. 1995;151(3 Pt 1): 879-886.

45. Rohde G, Wiethege A, Borg I, et al. Respiratory viruses in exacerbations of chronic obstructive pulmonary disease requiring hospitalisation: a case-control study. Thorax. 2003;58(1):37-42.

46. Papi A, Bellettato CM, Braccioni F, et al. Infections and airway inflammation in chronic obstructive pulmonary disease severe exacerbations. Am J Respir Crit Care Med. 2006;173(10):1114-1121.

47. Ko FW, Ip M, Chan PK, et al. A 1-year prospective study of the infectious etiology in patients hospitalized with acute exacerbations of COPD. Chest. 2007;131(1):44-52.

48. Wilkinson TM, Hurst JR, Perera WR, Wilks M, Donaldson GC, Wedzicha JA. Effect of interactions between lower airway bacterial and rhinoviral infection in exacerbations of COPD. Chest. 2006;129(2): 317-324.

49. Camargo CA Jr, Ginde AA, Clark S, Cartwright CP, Falsey AR, Niewoehner DE. Viral pathogens in acute exacerbations of chronic obstructive pulmonary disease. Intern Emerg Med. 2008;3(4):355-359.

50. Ko FW, Ip M, Chan PK, Ng SS, Chau SS, Hui DS. A one-year prospective study of infectious etiology in patients hospitalized with acute exacerbations of COPD and concomitant pneumonia. Repir Med. 2008;102(8):1109-1116. 
51. Scott EJ, Grist NR, Eadie MB. Rhinovirus infections in chronic bronchitis: isolation of eight possibly new rhinovirus serotypes. $\mathrm{J} \mathrm{Med}$ Microbiol. 1968;1(1):109-117.

52. Gump DW, Phillips CA, Forsyth BR, McIntosh K, Lamborn KR, Stouch WH. Role of infection in chronic bronchitis. Am Rev Respir Dis. 1976;113(4):465-474.

53. Philit F, Etienne J, Calvet A, et al. Infectious agents associated with exacerbations of chronic obstructive bronchopneumopathies and asthma attacks. Rev Mal Respir. 1992;9(2):191-196. French.

54. Seemungal T, Harper-Owen R, Bhowmik A, et al. Respiratory viruses, symptoms, and inflammatory markers in acute exacerbations and stable chronic obstructive pulmonary disease. Am J Respir Crit Care Med. 2001;164(9):1618-1623.

55. Greenberg SB, Allen M, Wilson J, Atmar RL. Respiratory viral infections in adults with and without chronic obstructive pulmonary disease. Am J Respir Crit Care Med. 2000;162(1):167-173.

56. Mallia P, Message SD, Kebadze T, Parker HL, Kon OM, Johnston SL. An experimental model of rhinovirus induced chronic obstructive pulmonary disease exacerbations: a pilot study. Respir Res. 2006;7:116.

57. Mallia P, Message S, Contoli M, et al. An experimental model of virus induced chronic obstructive pulmonary disease exacerbation. Thorax. 2006;61(Suppl 2):Sii3-Sii56. Available from: http:/www.ncbi.nlm nih.gov/pmc/articles/PMC2104786/. Accessed August 2, 2012.

58. Mallia P, Message SD, Gielen V, et al. Experimental rhinovirus infection as a human model of chronic obstructive pulmonary disease exacerbation. Am J Respir Crit Care Med. 2011;183(6):734-742.

59. Crump CE, Arruda E, Hayden FG. Comparative antirhinoviral activities of soluble intercellular adhesion molecule-1 (sICAM-1) and chimeric ICAM-1/immunoglobulin A molecule. Antimicrob Agents Chemother. 1994;38(6):1425-1427.
60. Turner RB, Wecker MT, Pohl G, et al. Efficacy of tremacamra, a soluble intercellular adhesion molecule 1, for experimental rhinovirus infection: a randomized clinical trial. JAMA. 1999;281(19):1797-1804.

61. Savolainen C, Blomqvist S, Mulders MN, Hovi T. Genetic clustering of all 102 human rhinovirus prototype strains: serotype 87 is close to human enterovirus 70. J Gen Virol. 2002;83(Pt 2):333-340.

62. Saito T, Hirai R, Loo YM, et al. Regulation of innate antiviral defenses through a shared repressor domain in RIG-I and LGP2. Proc Natl Acad Sci U S A. 2007;104(2):582-587.

63. Hayden FG, Herrington DT, Coats TL, et al; for Pleconaril Respiratory Infection Study Group. Efficacy and safety of oral pleconaril for treatment of colds due to picornaviruses in adults: results of 2 double-blind, randomized, placebo-controlled trials. Clin Infect Dis. 2003;36(12):1523-1532.

64. Arnold E, Luo M, Vriend G, et al. Implications of the picornavirus capsid structure for polyprotein processing. Proc Natl Acad Sci USA. 1987;84(1):21-25.

65. König H, Rosenwirth B. Purification and partial characterization of poliovirus protease $2 \mathrm{~A}$ by means of a functional assay. $J$ Virol. 1988;62(4):1243-1250.

66. Alexis NE, Lay JC, Almond M, Bromberg PA, Patel DD, Peden DB. Acute LPS inhalation in healthy volunteers induces dendritic cell maturation in vivo. J Allergy Clin Immunol. 2005;115(2):345-350.
International Journal of COPD

\section{Publish your work in this journal}

The International Journal of COPD is an international, peer-reviewed journal of therapeutics and pharmacology focusing on concise rapid reporting of clinical studies and reviews in COPD. Special focus is given to the pathophysiological processes underlying the disease, intervention programs, patient focused education, and self management protocols.

\section{Dovepress}

This journal is indexed on PubMed Central, MedLine and CAS. The manuscript management system is completely online and includes a very quick and fair peer-review system, which is all easy to use. Visit http://www.dovepress.com/testimonials.php to read real quotes from published authors. 